
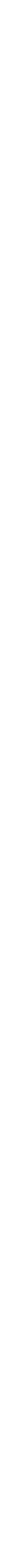


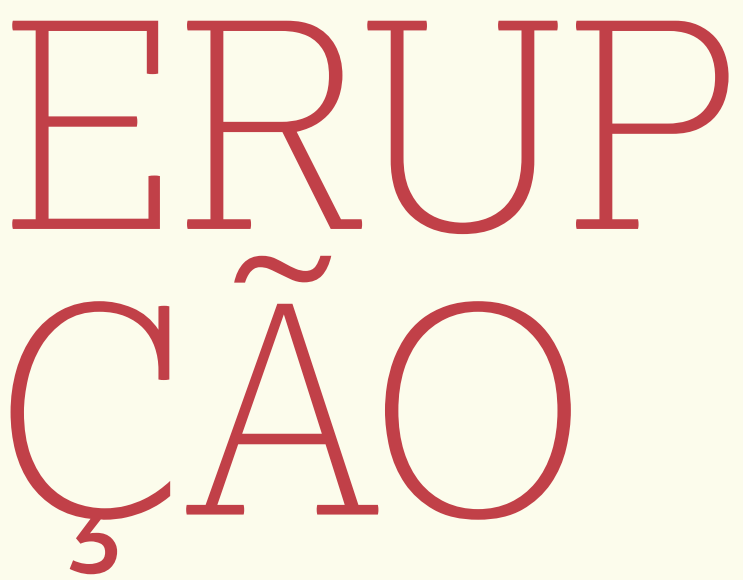

Do latim eruptio, -onis. Saída impetuosa.

Explosão, jacto de matérias.

Evento vulcânico. 


\title{
A EXPRESSÃO DO DRAMA DA LIBERDADE EM SARTRE
}

\author{
- FRANKLIN LEOPOLDO E SILVA
}

A s obras de ficção não são as únicas em que encontramos a expressão dramática da condição humana no pensamento de Sartre. Já foi notado pelos estudiosos de sua obra que os ensaios filosóficos muitas vezes trazem a expressão literária mesclada à análise conceitual-filosófica. E talvez o maior exemplo seja a obra mais conhecida do filósofo, O Ser e o Nada: embora se trate de um "ensaio de ontologia fenomenológica", há no livro abundantes exemplos de condutas que são elucidadas ontologicamente, e que se apresentam como pequenas narrativas, várias das quais poderiam constituir pequenos contos que conteriam em si mesmos significados vinculados ao tema da subjetividade. No capítulo sobre a má-fé, o relato do garçom, cujo comportamento indica uma gestualidade que o fixa demasiadamente em si mesmo, uma estratégia de fuga da liberdade por via da cristalização do Eu; a jovem que abandona sua mão entre as do sedutor, como se estivesse alheia a si mesma e, portanto, sem ter de assumir a situação. Tais exemplos, aos quais poderíamos acrescentar muitos outros, não são ilustrações incidentais da descrição teórica da má -fé; pelo contrário, constituem elementos intrínsecos à ontologia da conduta, perspectiva à qual se subordina o tratamento psicológico do comportamento.

Poderíamos dizer que uma ontologia fenomenológica da conduta do para-si comporta naturalmente tais relatos em estilo literário, e que nestes casos não poderíamos distinguir completamente a filosofia da literatura, devido à própria configuração temática do estudo. Se assim for, então temos de admitir que esta relação é intrínseca ao tratamento dos temas sartrianos e que, para além do estilo do escritor, o que se deve ressaltar é a vinculação estreita e o caráter inseparável do que habitualmente designamos como dois gêneros. Mas ainda é possível avançar um pouco mais no exame desta vinculação e de seu significado. Poderíamos dizer, 
a partir do estudo de Cristina Diniz Mendonça ${ }^{1}$, e simplificando a posição da autora, que O Ser e o Nada é um tecido de exemplos entremeado de comentários que deslindam o caráter filosófico das condutas narradas. Essa aparente inversão do que habitualmente consideramos ser a ordem que se estabelece entre análise e exemplos é extremamente significativa. Para aquilatar aspectos de seu alcance, pensemos na irredutível contingência do para-si, a espécie de precariedade ontológica que no entanto é condição da liberdade. O caráter afirmativo e tético do texto filosófico versa sobre a contingência característica da condição humana. Tal característica aparece, isto é, manifesta-se nos exemplos, os quais já traduzem a relativa gratuidade da existência antes mesmo que o texto filosófico fixe a reflexão que sobre isto se possa fazer. De modo que se torna inteiramente plausível considerar que a contingência da manifestação é matéria do discurso filosófico. As narrativas de conduta pautam, assim, a elaboração reflexiva da compreensão filosófica da existência.

Isto significa que a realidade em seu sentido mais intenso e mais patente seria o estrato fundamental do livro, e que a conceituação desta realidade decorre de sua afirmação. Isto não quer dizer apenas que a preocupação primária do filósofo é com a realidade que se trata de esclarecer. $\mathrm{O}$ que temos aí também é a imanência do significado à vida, de acordo com a prioridade fenomenológica da vivência. $\mathrm{O}$ apelo aos fatos, e à contingência que eles manifestam é inseparável da significação atribuída, isto é, vivida, pela consciência. Esta, por estar sempre fora de si, projetando-se temporalmente, vive os significados que simultaneamente constitui. Neste sentido, a relação de imanência entre facticidade e significação modela e modula a experiência da liberdade. Assim a noção de existência estará sempre lastreada pela "aventura humana" em sua dramaticidade. A historicidade é dramática.

Atualmente, penso que a filosofia é dramática. Já não se trata de contemplar a imobilidade das substâncias que são o que são, nem de encontrar as regras de uma sucessão de fenômenos. Trata-se do homem - que é ao mesmo tempo um agente e um ator - que produz e vive seu drama, vivendo as contradições de sua situação até a explosão de sua pessoa ou até a solução de seus conflitos. ${ }^{2}$

A atualidade da filosofia exige sua dramaticidade. Se toda filosofia é expressão de sua época, a filosofia de uma época dramática - dividida e contraditória - só poderá ser o registro destes conflitos. E a meditação sobre eles certamente não será uma contemplação, porque as coisas humanas não são o que são e sim as contradições de que se revestem,
[1] Mendonça, C. D. O mito da Resistência. Experiência histórica e Forma filosófica em Sartre. Tese de Doutoramento, FFLCH-USP, 2001.

[2] "Les Écrivains en Personne. Entrevista à Madeleine Chapsal". In: Sartre, J.P, Situations IX (Mélanges). Paris: Gallimard, p. 12. 
afastadas que estão de uma pacífica identidade. Longe de ser linear, a sucessão histórica é a revelação das contradições protagonizadas pelo sujeito enquanto agente histórico e ator do drama vivido historicamente. Neste sentido a condição humana enquanto sucessão de situações articula-se por via de uma dialética que não encontrará conciliação. São as tensões da vida histórica que a filosofia da existência pretende compreender em seu caráter intrinsecamente conflituoso. A existência não é um fenômeno objetivo e a sucessão vivida não pode ser compreendida de forma categorial.

\footnotetext{
Uma peça de teatro (épica - como as de Brecht - ou dramática), é a forma mais apropriada, atualmente, para mostrar o homem em ato (isto é, o homem, simplesmente). E a filosofia, de um outro ponto de vista, é deste homem que ela pretende se ocupar. É por isto que o teatro é filosófico e a filosofia é dramática. ${ }^{3}$
}

Já que a filosofia se ocupa da existência, o que interessa é o homem "em ato"; mas como a existência não se segue de uma essência determinada, o homem é sempre em ato: o homem simplesmente homem se define pela ação, e antes de tudo pelo modo como age fazendo-se a si mesmo. Por isto a compreensão filosófica da condição humana refere-se sempre aos atos, pois a ausência de ação seria a inexistência, já que nada há que defina o homem antes do ato de existir. Neste sentido a ação dramatúrgica é a forma "mais apropriada" para mostrar a existência - o sujeito em ato, porque o teatro é a dramatização da existência. E como a filosofia visa o sujeito em ato, ela ocorre de modo paralelo à literatura, o que significa que a literatura dramática é filosófica e a filosofia é dramática. Evidentemente, não se trata de postular a identidade dos gêneros; eles permanecem diferentes e demarcados em seus procedimentos. $\mathrm{O}$ que Sartre deseja marcar é a reciprocidade que deriva de um mesmo propósito. É o que nos faz compreender, também, a relação entre o filósofo e o escritor num mesmo autor. Relação que corresponde a uma exigência histórica, que é a compreensão da experiência, que, na atualidade, necessita ser igualmente interrogada pela filosofia e pela literatura. A adequação da conduta interrogante passa pela convergência dos dois horizontes de compreensão e de expressão.

A razão dessa convergência é a relação entre existência e história. Não é preciso esperar pela Crítica da Razão Dialética para sabermos que a existência é histórica. Em O Ser e o Nada, a elucidação ontológica, por ser fenomenológica, já contempla a experiência histórica do homem em situação, isto é, a vivência concreta da tensão entre liberdade e de- 
terminação. Os exemplos, que já mencionamos, cumprem esta função importante de descrever a conduta, tanto no plano de suas possibilidades ontológicas quanto no que concerne à história vivida. E isto ocorre considerando dois planos: o da história individual ou temporalidade vivida pelo sujeito; e o da História em geral, na qual se insere a história singular de modo complexo, por via das tensas relações que se dão entre as condições subjetivas e objetivas às quais o sujeito deve corresponder no exercício de sua liberdade. O que coloca o problema da compreensão do projeto, o meu e o dos outros. É possível chegar a tal entendimento? $\mathrm{O}$ jogo das possibilidades humanas faz com que o projeto se estruture no contexto da história subjetiva e da história objetiva, sempre de forma a que essa tensão seja "produtora" dos resultados, frutos das escolhas, que por sua vez se dão no âmbito da dupla dimensão histórica. Em princípio podemos compreender qualquer projeto humano ${ }^{4}$ o que não quer dizer que possamos elaborar uma explicação analítica a respeito. Posso compreender como o sujeito vive as situações sintéticas nas quais são feitas as escolhas, embora não possa fornecer razões suficientes que explicariam as ações ao modo de uma causalidade convencional. Justamente, trata-se de compreender as escolhas e a articulação que entre elas se dá na relação entre o projeto fundamental e as opções que o explicitam sem nunca realizá-lo em totalidade. $\mathrm{O}$ mundo já é dado ao sujeito de forma sintética, não para que ele o analise em seus elementos, mas para que o indivíduo nele se insira de acordo com as tensões entre história singular e história geral.

Encontramos esta perspectiva expressa, no caso da ficção, já desde o relato de $O$ Muro, que pode ser visto como a descrição da tensão entre o modo como o indivíduo tenta se inserir subjetivamente na história de que participa, e a força das condições objetivas que sobre ele pesa. De modo semelhante, a atitude de Mathieu perante a guerra na narrativa Caminhos da Liberdade. Ele não consegue expor ao irmão as razões que o fazem atender à convocação militar, mas está de qualquer forma mobilizado: este termo, além do significado propriamente militar, denota ainda a situação existencial: ele está comprometido com a guerra, mas este compromisso não deriva de razões "objetivas", como por exemplo, um conhecimento pormenorizado das pendências acerca dos territórios em disputa, ou outros aspectos de política internacional. Muito embora estes fatores estejam presentes, pois deles decorre a própria guerra, o mais relevante é a inserção subjetiva na situação. Ou seja, trata-se de uma escolha cujas causas "objetivas" ou critérios externos não atuam decisivamente. $\mathrm{O}$ que importa é o ato de engajamento, independente da clareza que aí se apresenta. Esta guerra é minha guerra: a assunção de
[4] Cf. a respeito O Ser e o Nada, tradução brasileira de Paulo Perdigão. Petrópolis: Vozes, 2001, p. $536 \mathrm{ss}$. 
responsabilidade a partir da espontaneidade da liberdade; o sujeito "em ato", significando que nem sempre a ação sucede à reflexão, como se houvesse uma vivência pré-reflexiva da experiência e das possibilidades que se delineiam. No limite, seria possível se perguntar até mesmo se se trata de escolha. Mas esta pergunta seria suscitada pelo nosso hábito de entender a escolha como um resultado de uma certa aferição de motivos ou razões. Sabemos que a presença de qualquer a priori transformaria a liberdade em determinação; não se trata, evidentemente, da autonomia em sentido kantiano, mas da liberdade enquanto expressão de si. Não há motivos analiticamente discerníveis porque é o sujeito em seu processo de totalização que decide.

Ora, este processo, que não corresponde a uma análise das condições objetivas, é, no entanto, a expressão de uma subjetividade em situação, isto é, às voltas com a dimensão objetiva desta situação. Não significa que a guerra seja determinante em sentido absoluto: o pacifista, o covarde, o oportunista são figuras desenhadas por Sartre para indicar outras possibilidades - outras escolhas, com seus graus de radicalidade: o militante pacifista arriscará sua vida para não ir à guerra. $\mathrm{O}$ fato de que Mathieu parece não considerar outra opção indica que a escolha é uma expressão total de si mesmo ("minha guerra").

Esta atitude deve ser expressa dramaticamente, inclusive para que a dimensão objetiva do conflito apareça como vivida. É desta maneira que a expressão literária é vista como "apropriada". A descrição da experiência emocional que faz com que o sujeito assuma a situação como seu projeto, ainda que isto não tenha sido objeto de deliberação anterior. O que encontramos na narrativa da trilogia sartriana é a expressão dramática da tensão entre a liberdade como disponibilidade e a liberdade como compromisso. Acerca do primeiro sentido podemos perguntar: liberdade para quê? Acerca do segundo podemos arguir acerca da justificativa da decisão. O protagonista não pode responder a nenhuma das duas questões e por isto parece que a decisão é gratuita, como notará o irmão de Mathieu, Jacques. Mas a questão de fundo, ou o fundo existencial da questão, diz respeito à necessidade de uma ordem de razões para que o sujeito livremente se comprometa. E muitas vezes em Sartre a ausência de causa assumirá a aparência da gratuidade.

É acerca desta questão que, em O Existencialismo é um Humanismo, Sartre fará a comparação com a obra de arte - a posição do artista diante da obra.

Efetivamente, ele escolhe sem se referir a valores preestabelecidos, mas é injusto acusá-lo de capricho. Digamos antes que devemos com- 
parar a escolha moral à construção de uma obra de arte. [...] alguma vez se acusou um artista que faz um quadro de não se inspirar em regras estabelecidas a priori? Alguém, alguma vez, lhe indicou que quadro deveria fazer? Qual a relação de tudo isto com a moral? Trata-se da mesma situação criadora. Nunca falamos na gratuidade de uma obra de arte. Quando nos referimos a uma tela de Picasso, nunca dizemos que ela á gratuita; compreendemos perfeitamente que ele se construiu a si mesmo, tal qual é, ao mesmo tempo que pintava, que o conjunto de sua obra se incorpora à sua vida. ${ }^{5}$

Esta comparação entre a moral e a arte, no que concerne ao caráter inventivo e criativo de ambas, deve respeitar a intenção de Sartre em dois pontos importantes: primeiramente, não se trata de uma estetização da ética; em segundo lugar, pela negação do caráter gratuito deve-se entender que a compreensibilidade da obra e do ato moral provém de que se trata de uma expressão do sujeito, não apenas de seu foro íntimo ou de sua "alma" mas de sua subjetividade concreta. É isto que permite compatibilizar a independência em relação a fatores diretamente condicionantes com o compromisso ou o engajamento. No mesmo sentido em que a arte não precisa estar "a serviço" de uma causa para se comprometer com ela, também a escolha moral do ato não precisa ser determinada para ser comprometida. $O$ verdadeiro compromisso deriva da liberdade. E acontece não por causalidade linear, mas pelo processo dramático em que consistem as escolhas existenciais, que são ao mesmo tempo históricas e políticas. Testemunho desta diferença é a figura do comunista Brunet em Caminhos da Liberdade. Diante de Mathieu, aparentemente hesitante e confuso, Brumet aparece dotado da segurança derivada do que ele mesmo designa como entrega da liberdade ao Partido. Neste sentido questiona Mathieu acerca do que fazer com a liberdade. Este resiste em concordar que o sentido da liberdade consiste na entrega que fez Brunet. Assim permanece a ambiguidade ou a tensão entre a liberdade como disponibilidade e a liberdade como compromisso. No primeiro caso, pode existir o vazio que assinala Brunet; no segundo o dogmatismo alienante de que desconfia Mathieu.

O exercício da liberdade é um drama, sobretudo quando referido a condições históricas concretas, isto é, opções possíveis. A dramaticidade do tempo histórico faz com que a história subjetiva se passe dramaticamente, o que é expresso no conflito entre os sentidos da liberdade (os "caminhos") que mencionamos acima. É preciso entender que a liberdade como disponibilidade não se completa, porque o sujeito é o que $f a z$ e antes de tudo, o que faz de si mesmo. Por outro lado, a entrega da
[5] Sartre, J.P. "O Existencialismo é um Humanismo" In: Sartre. Coleção Os Pensadores. Tradução brasileira de Rita Guedes. São Paulo: Nova Cultural, 1987, p. 18. 
[6] Sartre, J. P. "Questão de Método". In: Sartre. Coleção Os Pensadores. Tradução brasileira de Bento Prado Jr. São Paulo: Nova Cultural, 1987, p. 125 - nota 14. liberdade é ainda uma escolha livre, mas acerca da qual cabe questionar a autenticidade. É de alguma forma entre estes dois caminhos que se dá o exercício da liberdade. A história nos solicita, não como uma instância extrínseca, mas no modo de uma relação interna entre o objetivo e o subjetivo, pois a história que vivemos é a história que fazemos, e ela nos faz tanto quanto nós a fazemos. Nisto consiste o drama do agir humano e, principalmente, as contradições, tantas vezes constatadas, ente as intenções e os resultados.

O motivo pelo qual Sartre torna-se filósofo e escritor reside na diferença entre as possibilidades do conceito e as possibilidades da imaginação. Não se trata de estabelecer uma comparação e muito menos uma hierarquia. Se a literatura pode mostrar o sujeito em ato, a filosofia da existência também pretende fazê-lo - e é esta a sua originalidade frente à tradição. Na verdade, a filosofia como antropologia estrutural e histórica orienta-se pelo esclarecimento da ação, isto é, do fazer pelo qual o indivíduo se constitui e é constituído.

O princípio metodológico que faz começar a certeza pela reflexão não contradiz de forma alguma o princípio antropológico que define a pessoa concreta pela sua materialidade. A reflexão, para nós, não se reduz à simples imanência do subjetivismo idealista: só é um início se nos lança imediatamente entre as coisas e os homens. ${ }^{6}$

Advertência importante, desde que entendamos que a "materialidade" da pessoa não se deduz da metafísica materialista, mas engendra um saber em que o objetivo e o subjetivo estão dialeticamente articulados, por via das disciplinas que Sartre convoca para constituir o método compreensivo que Questão de Método introduz e que a Crítica da Razão Dialética desenvolve em seus procedimentos e consequências.

De acordo com esta orientação, evitamos tanto o idealismo quanto o realismo. E este caminho se traça quando começamos por substituir a questão cartesiana "Quem sou Eu?" (o que é o ser pensante?) pela indagação acerca do para-si. Já na Transcendência do Ego Sartre havia afirmado o caráter construído e externo do Eu enquanto aparelho psíquico e as considerações metafísicas que sobre ele se possa fazer. É necessário abandonar a abordagem metafísica da interioridade e adotar uma ontologia como descrição fenomenológica da experiência subjetiva. É esta descrição compreensiva que ocorre por meio de uma conduta interrogante que será explorada pela literatura. Tanto na filosofia quanto na ficção a reflexão está presente, sempre orientada pelo sentido da materialidade da pessoa. Assim, é precioso observar que Sartre não se furta à aborda- 
gem de temas metafísicos, mas na "atualidade" tais temas já não serão a identidade da substância ou a relação entre tempo e eternidade; o interesse desloca-se para a metafísica do homem ou o que Merleau-Ponty designa como o metafísico no homem. ${ }^{7}$ Esta nota característica da ficção sartreana foi ressaltada por A. Camus, já por ocasião de sua resenha da novela A Náusea: "Um romance nunca passa de uma filosofia posta em imagens". ${ }^{8}$ Também aqui não se trata de opor rigidamente, no contexto sartreano, conceito e imagem. A observação de Camus deve nos levar a entender que, se a literatura privilegia as imagens, o texto filosófico também delas se vale para uma aproximação mais precisa do que é preciso dizer. Precisão que Bergson já havia assinalado ao considerar o papel da metáfora na compreensão filosófica.

É neste sentido que o romance e o teatro cumprem a função antropológico-filosófica de apresentar o sujeito em ato, às voltas com suas ações, seus projetos e suas contradições, na permanente busca da totalização de si. A finalidade e a vocação do conceito aparecem habitualmente como relação adequada entre representação e realidade. Muito embora não se considere, em Kant, por exemplo, que seja possível uma representação completa da realidade, que nos restituiria integralmente as coisas tais como são em si mesmas, o Índice de verdade objetiva da representação conceitual é suficiente para a articulação do conhecimento, ao menos fenomênico. $E$ a certeza nos é assegurada pelo sujeito, no caso pela estrutura subjetiva dos elementos a priori que atuam como condições da representação objetiva. Se o conceito não nos pode dar acesso ao real em sua totalidade, ao menos ele representará totalmente o que podemos saber acerca das coisas. Os limites epistemológicos seriam parte integrante do conhecimento verdadeiro tal como podemos postulá-lo em teoria. A filosofia hegeliana procurará restituir à Razão a prerrogativa da totalidade, superando assim as restrições que Kant fizera à atividade do entendimento.

Ora, logo no início de O Ser e o Nada, Sartre afirma que o grande passo dado pelo pensamento moderno teria sido "reduzir o existente à série de aparições que o manifestam" substituindo os dualismos pelo "monismo do fenômeno". ${ }^{9}$ Esta afirmação, que poderia ser tomada como uma homenagem a Kant, tem, no entanto, o seu alcance diminuído pela pergunta que se segue: "Isso foi alcançado?". Não vamos aqui expor a crítica de Sartre à estratégia moderna de redução do ser à representação, o que ele entende que não ocorreu inteiramente. Basta mencionar a relevância da questão para Sartre, já que ela constitui uma espécie de fio condutor da investigação. "Se a essência da aparição é um 'aparecer' que não se opõe a nenhum ser, eis aqui um verdadeiro problema: o do ser deste aparecer". ${ }^{10}$
[7] Merleau-Ponty, M. "Le métaphysique dans l'homme". In: Sens et non-sens. Paris: Nagel, 1966. Cf. p. 167-168: "La métaphysique n'est pas une construction de concepts par lesquels nous essaierons de rendre moins sensible nos paradoxes; c'est l'expérience que nous em faisons dans toutes les situations de l'histoire personelle et colective - et des actions que, les assumant, les transforment en raisons". Cf também o ensaio, na mesma coletânea, sobre o romance $A$ Convidada de Simone de Beauvoir, "Le Roman et la Métaphysique", p. 45ss.

[8] Camus, A. "A Náusea, de Jean-Paul Sartre”. In: A Inteligência e o Cadafalso. Rio de Janeiro: Record, 1998, p. 133.

[9] Sartre, J. P. O Ser e o Nada, op. cit., p. 15.

[10] Sartre, J. P. O Ser e o Nada, op. cit., p. 18. 
[11] Les Écrivains em Personne. Situations IX, op. cit., p. 31.

[12] Sartre, J. P. Que é a Literatura? Tradução brasileira de Carlos Felipe Moisés. São Paulo: Ática, 1989, p. 209.
Ao tocar nesta questão queremos apenas indicar que a função da literatura é fazer com que o homem apareça a si mesmo, mas como num "espelho crítico". "O homem vive rodeado por suas imagens. A literatura lhe dá a imagem crítica de si mesmo. [...] Um espelho crítico. Mostrar, demonstrar, representar. É isto o engajamento, depois, as pessoas se olham e farão o que quiserem"11. A responsabilidade do escritor é considerar que ele se dirige a homens livres que, embora vivendo numa determinada conjuntura histórica, seriam capazes de reconhecer-se criticamente. Não de acordo com o que fizeram deles, mas de acordo com o que podem fazer com isto que fizeram deles. Assim, a primeira atitude do escritor é reconhecer a liberdade dos outros, a partir da própria liberdade de pensamento que reivindica para si. $\mathrm{O}$ aparecer do homem a si mesmo é a parte mais relevante de sua condição de sujeito e, no contexto sartriano não significa por certo uma representação fixada de modo essencial, mas o reconhecimento da historicidade, do projeto e da possibilidade de tornar-se sempre outro. Quando isto não acontece, temos a "consciência mistificada" e a obrigação do escritor é então desempenhar a tarefa de desmistificação.

\footnotetext{
Mas, como o escritor se dirige à liberdade de seu leitor e como cada consciência mistificada, enquanto cúmplice da mistificação que a aprisiona, tende a perseverar neste estado, só poderemos salvaguardar a literatura se assumirmos a tarefa de desmistificar o nosso público. Pela mesma razão, o dever do escritor é tomar partido contra todas as injustiças, de onde quer que venham. ${ }^{12}$
}

No contexto da experiência dramática da liberdade, a literatura está diante de duas tarefas: desmistificar e tomar posição contra as injustiças "de onde quer que venham". Mas seria legítimo atribuir à literatura funções ou tarefas? Na verdade, não se trata de uma função a ser desempenhada no sentido positivo do termo. Numa sociedade em que imperam a mistificação e a injustiça, a liberdade exerce seu poder de negação, que é como que a sua primeira figura. Não se trata tanto de restabelecer a consciência autêntica nem a justiça, mas principalmente de negar a realidade dada. Ao propiciar o reconhecimento da iniquidade, a literatura está oferecendo o "espelho crítico" e, como diz Sartre, as pessoas se olharão e depois farão o que quiserem. Na medida em que se dirige à liberdade do leitor, o escritor nada lhe impõe e a literatura não cultiva a pretensão de reformar a sociedade. $\mathrm{O}$ que faz é proporcionar ao leitor a oportunidade de se mirar na dramaticidade que o constitui. Ele permanece livre para mudar ou para perseverar na mistificação. Assim, qualquer tentativa de mostrar ou representar a liberdade é primeiramente o ato de negar 
a alienação. Como o próprio escritor está submetido às injunções, "fui conduzido a pensar sistematicamente contra mim mesmo", ${ }^{13}$ inclusive quando, "(d)urante muito tempo, tomei minha pena por uma espada: agora conheço nossa impotência". ${ }^{14}$ Significa isto o reconhecimento de si no fracasso da escrita? Ou temos aí, para voltar à filosofia, um aspecto da frustração constitutiva do processo de subjetivação, a "paixão inútil" de que nos falam as páginas finais de O Ser e o Nada. O que estaria de acordo com a função expressiva da literatura, a qual só pode ocorrer a partir da existência histórica primeiramente vivida em sua efetividade. I
[13] Sartre, J.P. As Palavras. Tradução brasileira de J. Guinsburg. São Paulo: DIFEL, 1964, p. 156.

[14] Sartre, J.P. As Palavras, op. cit., p. 157.

FRANKLIN LEOPOLDO E SILVA - Professor Aposentado do Departamento de Filosofia da Faculdade de Filosofia, Letras e Ciências Humanas (FFLCH) da Universidade de São Paulo (USP). O texto foi apresentado na palestra de abertura do VI Seminário de Pesquisa do Programa de Teoria Literária e Literatura Comparada, no dia 13 de abril de 2015. 